\title{
TEACH ENGLISH, CONFRONT SEXISM \\ EMPOWERING STUDENTS AS CRITICAL THINKERS AND LANGUAGE USERS THROUGH A GENDER EQUALITY POSTMETHOD APPROACH \\ TO EFL TEACHING
}

\begin{abstract}
Elizabeth Sara Lewis has masters' degrees in Anthropology from the EHESS, Paris, France, and in Women's and Gender Studies from the Università degli Studi Roma Tre, Italy. She is currently finishing a master's in Language Studies at the PUC-Rio, Brazil.

E-mail: saraluis@gmail.com
\end{abstract}

\begin{abstract}
This article explores a gender-equality postmethod approach to teaching English as a Foreign Language. It describes and analyzes an action research project performed with an EFL class in Italy, in which the students were encouraged to think critically about sexism and English language use.
\end{abstract}

\begin{abstract}
Resumo
Este artigo propõe uma abordagem pós-método de igualdade de gênero para o ensino de inglês como língua estrangeira. Relata-se uma pesquisa-ação realizada com um grupo de alunos/as italianos/as com a qual os/as estudantes foram encorajados/as a pensar criticamente sobre língua inglesa e sexismo.
\end{abstract}

\section{1) Introduction}

Words are never sexist in and of themselves; it is how they are used in certain contexts that can be sexist. Unfortunately, didactic materials often perpetuate sexist stereotypes, and teaching methodologies do not always impart the critical thinking skills necessary for their deconstruction. This creates a particularly complicated situation for students of English as a Foreign Language (EFL, henceforth), who often learn new words and grammatical structures but not the connotations they can have in different situations and socio-cultural contexts. This is further complicated by the ideas that stereotypes are helpful or even "necessary" for foreign language acquisition (Fiske, 1998, p. 357-411) and that foreign language students should be taught a limited number of options for expressing themselves since they will supposedly become confused if they learn "too many" alternatives. Students thus learn grammatically correct but limited language, which often reinforces a male-centered (linguistic) world and can lead them to speak in sexist ways without intending to do so. Unaware of the various options and their potential connotations in different contexts, students cannot act as agents making informed, situated linguistic choices.

Desiring to explore and change this situation, I realized an action research project in November 2007, in a month-long intensive pre-intermediate level EFL class with a group of 10 students in Rome, Italy. I created original didactic materials with the aim of representing gender equality and showing diverse behaviors to break down the boundaries of gender stereotypes. I also employed what I call a gender-equality postmethod teaching approach, aimed at empowering students by teaching them various communicative options and their possible effects in different socio-cultural contexts, 
and encouraging them to think critically about these options and chose the one(s) they preferred. I thus hoped to achieve three interrelated objectives: (1) disprove the traditional idea that teaching EFL students multiple linguistic options for self expression would hinder their language acquisition, (2) teach grammar without separating forms from socio-cultural contexts, and (3) encourage my students to think critically about language in order to realize empowered discursive performances in English. This article shall examine how the students assimilated these options and chose to put them into use while communicating, and show that avoiding and/or confronting stereotypes and teaching various options to students enhanced, rather than hindered, their foreign language acquisition, linguistic competencies and agentive possibilities. Although the course included a great variety of topics related to gender, due to the scope of this article the analysis shall focus on the lessons about the use of gender-marked and genderunmarked job-related lexical items and the ensuing discussions on gender stereotypes and professions.

The rest of this article shall be structured in the following manner: the second section of this article shall begin with a brief look at recent literature on sexist language uses and EFL teaching. The third section shall include a discussion of sexist uses of English in daily life and teaching materials, focusing on uses of morphosyntactic structures that perpetuate sexist cultural attitudes (particularly false generics, certain suffixes and unnecessary gender-marking modifiers) and some examples of sexism in EFL textbooks used in Italy. In the fourth section, the action research didactic project shall be described in detail, including information on the students, student-teacher relationship, course topics and materials, and an explanation of the gender-equality postmethod teaching approach. The fifth section shall contain the observations and analysis of the action research project, examining activities involving gender-marked and gender-unmarked professions vocabulary and the students' reactions to them, as well as considerations about how what was learned affected the students' language use during the remainder of the course.

\section{2) Recent literature on sexist language uses and EFL teaching}

In the 1980s, efforts to eliminate "linguistic sexism" had already gained a good deal of support in the public and private spheres of English-speaking countries. The Handbook of Nonsexist Writing, by Casey Miller and Kate Swift (1980), discusses the socio-linguistic history of sexism in the English language and offers gender-equality alternatives to common sexist uses. Similar works followed, including The Nonsexist Word Finder: A Dictionary of Gender-Free Usage, by Rosalie Maggio (1987).

Even before this, from 1970 on, various authors had showed interest in manifestations of sexism in EFL textbooks. In "Sexism and TESOL Materials" (1978), Hartman and Hudd studied various textbooks and found that the materials reflected sexist attitudes and values that reinforced women's status as "the second sex". In For 
Men Must Work, Women Must Weep: Sexism in English Language Textbooks Used in German Schools (1980), Hellinger researched the problem of the lack of representation of women in texts, exercises and illustrations, finding that $93 \%$ of the people mentioned in written texts were male, and that the few women represented were rarely shown performing difficult, interesting or esteemed activities. In a highly influential 1984 study, "Sexism in Current ESL Textbooks", Porreca researched manifestations of sexism in textbooks and their consequences, analyzing, in particular, the problem of the omission of women, of "firstness" (when men are always mentioned before women) and of the lack of women shown as working professionals. Many other articles continuing and expanding upon Porreca's work have followed.

Articles on gender equality and foreign language teaching appear frequently in articles for EFL teachers, especially in journals such as the TESOL Quarterly. Of particular interest are Jacqueline Beebe's 1998 article, "Sexist Language and English as a Foreign Language: A Problem of Knowledge and Choice", regarding the importance of not avoiding discussions about sexism in the classroom; Karen Stanley's 2001 article, "Sexist Language in ESL/EFL Textbooks and Materials", which explores not only sexist uses of language in books but also the teacher's responsibility as a political agent in the classroom and students as agents who should learn the socio-linguistic implications of the words and grammatical structures they acquire; and Junmin Kuo's 2005 article, "Teaching ESL/EFL Students to Recognize Bias in Children's Literature”, on how the teacher can take an active posture in guiding students of all ages to recognize and think critically about gender stereotypes in children's literature, rather than avoiding the use of such materials.

\section{3) Sexist uses of English language in daily life and teaching materials}

Language is our means of classifying and ordering the world: our means of manipulating reality. In its structure and in its use we bring our world into realisation, and if it is inherently inaccurate, then we are misled. If the rules which underlie our language system, our symbolic order, are invalid, then we are daily deceived. (Spender, 1980, p. 1)

Like other languages, English is full of forms that can be used in ways that discriminate against a group of people. Although men are not exempt from linguistic sexism, women tend to be more affected. In modern English, many unconscious prejudices expressed through language come from cultural attitudes towards women, and, to a lesser but nonetheless important extent, from cultural attitudes than can be damaging to men (Miller and Swift, [1980] 2001, p. ix). I shall now discuss some morphosyntactic structures than can be used in ways that perpetuate sexist cultural attitudes, particularly false generics such as "man", suffixes such as "-man" and the socalled "feminine" suffixes "-ess" and "-trix", and unnecessary gender-marking 
modifiers. I shall close this section by analyzing some examples of sexism in EFL textbooks used in Italy.

\section{1) "Man" as a false generic, suffixes and modifiers}

According to Miller and Swift, the transformation of the word "man" over the last thousand years is the most problematic and significant change ever to involve an English word ([1980] 2001, p. 8). Originally, the word "man" was synonymous with "human being"; however, its meaning in English gradually became more and more restricted, and it is currently used more as a synonym of male human adult (ibid). Those who would argue that using "man" and "he" in a generic sense does not mark women as "other" should consider examples such as, "As for man, he is no different from the rest. His back aches, he ruptures easily, his women have difficulties in childbirth..." (cited in Miller and Swift, [1980] 2001, p. 15). If, in this case, "man" and "he" were truly generic terms, the author would have written "he has difficulties in childbirth"; however, the author slides from the generic use to a specific one, marking women as "other". As alternatives to such false generics, Miller and Swift, in their book The Handbook of Nonsexist Writing, suggest using alternatives such as "human beings", "the human species", "Homo sapiens", "human societies", "we", "us", "one", "person/people", "individual(s)", etc., all of which provide sound options for expressing oneself in a more gender-equal fashion (p. 158) . $^{\mathrm{i}}$

With regards to the morpheme "-man" used as a suffix, some linguists insist that words thus formed (e.g. spokesman, chairman, etc.) are always gender-neutral. The Oxford English Dictionary, however, shows that for hundreds of year the majority of words ending in "-man" have been considered to be references to men only, as words ending in "-woman" refer only to women. Today, we frequently see contradictions in prescriptions for usage. The New York Times Manual of Style and Usage (1982), for example, permits the use of both "saleswoman" and "salesman", but prohibits the use of "spokeswoman" or "spokesperson", insisting that "spokesman" be used to refer to any gender. However, the words "spokeswoman" and "spokesperson" have actually been recognized for over 300 years; in fact, "spokeswomen" was cited in the Oxford English Dictionary in 1654, 50 years before "saleswoman" appeared in 1704 (cited in Miller and Swift, [1980] 2001, p. 30-32).

Using the suffix "-man" as a false generic can also imply that women are not equipped for performing certain jobs. However, it can also discriminate against men: when violence and crime are mentioned in the media, gender-marked words such as "gunman" tend to be used rather than gender-unmarked synonyms such as "shooter", "armed robber" or "armed intruder", even when the gender of the person who committed the crime is unknown. Therefore, although some of humanity's important achievements are often attributed to men through the false generic suffix "-man"; men also frequently receive the blame for crimes committed by humans in general (Miller 
and Swift, [1980] 2001, p. 23-24). Miller and Swift thus recommend using the suffix "woman" when applicable, choosing gender-unmarked suffixes such as "-person" or using gender-unmarked synonyms (such as "mail carrier" instead of "postwoman" or "postman"), particularly in situations where one is speaking of a mixed group (p. 3040).

The aforementioned example brings us to the issue of agent nouns (words derived from other words denoting actions, i.e. verbs, that identify an entity that performs said actions, as in "teach"/“teacher", "farm"/“farmer", etc.). In English, most agent nouns are gender-unmarked and can thus be used to refer to women or men. However, when gender-marked female suffixes of French or Latin origin, such as "-ess" and "-trix" are added to agent nouns to indicate a woman, the base form acquires a prevalently male sense and loses its gender-neutrality. A century ago, certain professions ending in the morpheme "-ess" were considered to be flattering since they underlined the courage and achievements of women who performed activities that were uncommon for ladies in that era. However, as time went on the use of such "feminine suffixes" as opposed to their gender-unmarked root word counterparts have taken on a negative connotation, suggesting that what is male is the norm and what is female is “abnormal” or "other" (Miller and Swift, [1980] 2001, p. 134-135).

Another way of using a gender-marked expression where one is not needed is by using modifiers such as "woman", "lady" or "female" (or "man" or "male"). Genderequality advocating linguists recommend avoiding forms such as "woman doctor" and "male nurse" because, as in the case with the "feminine suffixes", these unnecessary modifiers make it seem that the gender-unmarked word ("doctor", "nurse") is actually gender-marked and that the subject is performing an "abnormal" activity that does not correspond to gender conventions (Miller and Swift, [1980] 2001, p. 66-71).

\section{2) Sexist uses of language in EFL materials}

According to Porreca's 1984 study, the most common sexist uses of language found in EFL textbooks are: omissions (men are represented more frequently than women), "firstness" (when a woman and a man are mentioned, the man's name is almost always listed first) and professions (a great variety of professions are assigned to men; women are usually not represented as job-holders, or they are mentioned only as teachers, nurses and secretaries) (p. 101-128). Although a 2001 study by Karen Stanley showed some quantitative improvement with regards to the ratios of women and men mentioned in texts and portrayed in illustrations, it also noted little progress was made qualitatively: women are usually shown in "neutral" contexts (e.g. "Sarah is sitting"), or in negative contexts in which they are unable to cope with difficulties, while men are represented in positive contexts of success and winning (p. 3).

Sexism is also frequently present in linguistic choices in dialogues. The following is an extract from a pre-intermediate level EFL textbook used in Italian public 
schools and private learning institutions. In the following dialogue, two of the characters in the book, Meg, an 18-year old American girl, and Jeff, an English boy of approximately the same age, speak outside a restaurant before entering (Papa and Shelly, 2004, p. B15).

\author{
Jeff: Let's go in. I want that grilled salmon. \\ Meg: And I want a steak and some French fries. Uh, I'm sorry. I haven't got any \\ money with me. \\ Jeff: $\quad$ You women are always spending your money on make-up and clothes. So you \\ never have anything left for food. \\ Meg: Don't make me cross now. I just left my purse at home. \\ Jeff: Don't worry. It's your first date with me. Let me treat you.
}

This dialogue reinforces several negative generalizations regarding women: that they do not know how to save money, that they are only interested in clothes and makeup, and that they never want to pay for their own meals in restaurants. Although Meg responds to these generalizations by telling Jeff that her situation is different from what he has claimed, the fact that she does not react in a stronger, more assertive way (for example, by telling him that such sexist comments are unwelcome) allows the generalization to remain uncontested and therefore reinforced in the text. Finally, by telling Meg that he will pay for her food, Jeff's words reinforce the stereotypical, behavioral cultural convention that men should pay for women's meals.

Other types of sexism and reinforcement of gender stereotypes in textbooks are often evident in their illustrations. In the same textbook as the previous example, there are a series of photographs of Meg, her aunt Annie and her uncle Bill. While Bill relaxes on the sofa, Annie makes remarks about just having hoovered the floor and serves tea with biscuits. When some biscuits fall to the ground, Bill at first tells her not to worry about the mess, but then continues sitting on the couch and watching while Annie cleans it up (Papa and Shelly, 2004, p. A14-A15). A textbook with multiple representations of women and men doing the housework would not be problematic. However, in this book there are many illustrations such as the one described above and none of men doing similar chores; the totality reinforces stereotypical gender roles, namely the idea that women are responsible for cleaning the home, while men are not ${ }^{\mathrm{ii}}$.

\title{
4) The action research didactic project
}

The action research project was implemented in a private language institution in Rome, Italy, that offers government-financed intensive English courses free of charge to young, unemployed people. The project took place during one such intensive course, held from the $6^{\text {th }}$ to the $30^{\text {th }}$ of November, 2007, four hours per day, four times per week, for a total of sixty hours of lessons of general English at a pre-intermediate level. I shall begin by describing the students (whose names have been changed to protect 
their privacy) and the student-teacher relationship, followed by an account of the course topics and the materials created for the lessons, and finally an explanation of the genderequality postmethod teaching approach.

\section{1) The students and the student-teacher relationship}

The class was initially composed of 13 unemployed persons, although three found jobs and had to leave the course halfway through (as stipulated by the government sponsorship). The ten that attended the course assiduously from start to finish were aged 23 to 39 (with an average age of 30.6). Of those ten, six identified themselves as women on their enrolment forms, and four as men. With the exception of one who commuted daily from Viterbo, the rest all lived in Rome, albeit in very diverse neighborhoods with regards to geographical location and general socio-economic profile. As far as place of origin is concerned, three were from Rome or the Latium region, three from Sicily, two from Campania, one from Calabria, and one from Russia who had been living in Italy for seven years. I did not know the students prior to beginning the course, with the exception of one who had attended an intensive elementary level course taught by me earlier in the year.

Regarding their behavior in the classroom, I must say that in my eleven years of experience as a foreign language teacher, this group was one of the most participitative and motivated I have ever taught - they took part actively and attentively in all proposed activities, tried to speak as much English as possible, chatting very little in Italian, unabashedly asked questions and requested clarifications, and made efforts to apply the new concepts learned each day. I am sure that much of this was due to their own strong, personal motivation; however, I hope that my encouragement and active involvement as a teacher also played a part. Regarding my own behavior, I tried to instill a climate of mutual respect among all, and to replace the typical hierarchical relationship characterized by the "teacher-on-a-pedestal" with a more symmetrical relationship in which we all brought our own life experiences to the table and learned from each other, as suggested by Kumaravadivelu (1994, 2001), Brown (1997), and Richards and Rodgers (2001). I showed the group that I was always open to questions, suggestions and ideas, and encouraged as much respectful, open discussion and critical thinking as I could.

\section{2) The course topics and materials}

The general grammatical and lexical topics of the course, as per the requirements of the government-financing agency and the language school, were interrogative forms and question words (e.g. "who", "what", "when", "where", "why", "how", etc.), verb tenses for expressing future actions, modal verbs for making predictions (e.g. "will”, "may”, "might”, “won't"), expressing preferences (e.g. "I like”, 
"I would like", "I'd rather"), verb tenses for expressing past actions (focusing on the differences between using the present perfect and simple past tenses), indefinite pronouns (e.g. "whenever", "whoever", "everywhere", "everyone”, etc.), and professions vocabulary. Although these topics were required, I was given the freedom to teach them as I pleased and add any additional topics I thought relevant. I created my own didactic materials that promoted gender equality and discussions thereof. It is also important to note that although the students were aware that I was studying our in-class interactions and expressly gave their permission for me to record the lessons and analyze the recordings, they did not know that I was studying gender equality in particular and had prepared the classroom materials for that purpose.

With regards to these materials, as we saw in the previous section, EFL textbooks often contain images, dialogues and exercises that reinforce gender stereotypes and normative roles, portraying women in a passive and/or subordinate position. These stereotypes are reinforced both explicitly, as in dialogues in which a man expresses sexist sentiments and his female interlocutor does not react in an empowered way, or in images in which women and men realize activities and professions in accordance with stereotyped gender roles, and implicitly, as in phrases in which men are always portrayed as successful whereas women experience difficulties, or in examples that rarely mention women at all. Students can be influenced by these representations in materials used for EFL teaching (Sunderland, 1992, p. 86) in the same way that people become socialized subjects unconsciously influenced by the media (television, radio, film, newspapers, internet, etc.). As a consequence, this influence contributes to and reinforces sexist views present in their socio-cultural milieu (Sakita, 1995, p. 5).

For this course, I prepared authentic didactic materials with the aim of representing men and women as equally as possible (it is important to note that future extensions of this project should also include representations of transsexuals, transgendered individuals, genderqueer people, etc., as these were lacking in the original materials, although some discussions regarding such gender identities did surface during lessons). I also tried to break gender stereotypes by showing individuals with a wide range of "gendered" behaviors, rather than individuals boxed into the confines of stereotypically "female" or "male" ones. Following Irigaray's theory on language "conversion", I did not only try to offer possibilities for changing language by adding adequate terms; I also tried to transform discursive processes so that the students could (re)learn to communicate and "distinguish, label and name" ([1974] 1993, p. 254), making empowered choices on how to construct and perform discourse. It is important to note that my objective was to represent gender equality, not to invert the man-woman power hierarchy by performing a complete reversal of the sexist representations generally found in materials. As such, the materials created do not always show women in positions of success, power, superiority and domination, and men always in situations of difficulty, powerlessness, inferiority and subordination; the materials try to show 
women and men in a variety of situations, preferably ones that present a balance of power and effective communication between them. I shall give more concrete examples of these materials in the next section.

\section{3) The gender-equality postmethod teaching approach}

Of equal importance as the materials themselves are the behavior of and approach employed by the teacher. I chose, through an "enlightened eclecticism" (Brown 1997), a variety of methods based on what most interested students and was most effective in classes. Communicative Language Teaching was one of the most-used methods, relying heavily on role-play, as the students had good written comprehension and production skills but needed and wanted to improve competence in verbal communication. This mixed approach can be seen as "post-method", using a "pedagogy of particularity" adapted to local and institutional exigencies, the specific classroom context and students' needs, while valuing learner's individual experiences (Kumaravadivelu, 1994, 2001; see also Brown 1993, Silva 2004). Also, and most important for empowering students, was the emphasis on critical thinking and making informed linguistic choices; as Richards and Rodgers (2001) suggest, teachers should be intellectuals, since there is much more involved in being a language instructor than simply applying different methods.

As we observed in Section 3, the grammar and vocabulary presented in many textbooks reinforces a man-centered linguistic world, with false generics that, in practice in the world as it is today, exclude women or diminish their importance, even though in a strictly classical grammatical sense they ought to equally represent women and men. Traditional teaching ideas hold that teachers should not "risk" confusing students, particularly those at a beginning or pre-intermediate level, by teaching them "too many" options for lexical items and syntactic structures. Words and structures also tend to be taught divorced from political and social relationships of any type (Benson, 1997, p. 27). Students thus learn language that is very correct from a grammatical point of view, but limiting with regards to contextualized options for situated use. This language tends to reinforce a man-centered world and gender stereotypes, without giving students the possibility of making other linguistic choices. EFL students should be taught pragmatic, sociolinguistic aspects and ramifications of language-in-use, thus giving them the opportunity to make the language their own (Wolfson, 1989, p. 185), in other words, to empower themselves through (the foreign) language.

I consider these linguistic and socio-cultural competences, in combination with the critical thinking skills mentioned in the first paragraph, vital to the gender-equality aspect of the teaching approach. My desire during this action research project was to empower students to make informed linguistic choices; not to impose my own personal viewpoint on what kind of language should be used to combat sexism. In agreement with Peirce, students should understand that they do not use language only to reflect or 
to communicate, but to co-construct their socio-political positions (1995, p. 9-31). Teachers should thus empower them to: (1) understand how they could be judged in a given context and situation when using (gendered) language, (2) evaluate the language used and the message expressed by others, (3) understand why they encounter differences between how (gendered) English was used and how it could be interpreted in the past and in the present, and (4) to consider how their linguistic choices contribute to the evolution of the English language and to changes in (gender) relations (Beebe, 1998, n.p.). The teacher should also understand that every student will have her or his own ideas about what constitutes appropriate speech and take into account the fact that some may desire to transgress or subvert conventionalized gender roles and/or perform nonheteronormative gender (and sexuality) identities (ibid). Others may be tired of doing "gender monitoring" in order to perform or avoid performing a female or male persona while speaking their first language (ibid), welcoming the fact that English, through factors such as the absence of gender-inflected adjectives, gives them the opportunity to perform a more flexible or less marked gender identity. Some women may wish to speak more "like men" to challenge the patriarchal system or be more assertive and advance in a male-dominated workplace (Cameron, 1994, p. 382-398), while some men may wish to avoid projecting a hegemonic, normative masculinity through their speech.

Keeping such factors in mind, the aim of my post-method, gender-equality approach is to show more contextualized options to students, so that they can empower themselves through language and make critical, informed choices as to what lexical items and morphosyntactic structures to use. Trying to teach these options in a simple, clear way so as to not cause confusion, I hoped to achieve three objectives, as mentioned in the introduction: (1) disprove the traditional idea that EFL students have difficulties in assimilating multiple options for expressing themselves, (2) not divorce grammatical forms from their socio-cultural contexts, and (3) encourage my students to think critically and give them the necessary linguistic and socio-cultural competences to position, project and express themselves in a more empowered way in their English discursive performances.

Although my reasons for offering my students more contextualized linguistic options were so that they could choose for themselves how to use language, and although it was not my intention to force my viewpoint on them, I cannot say I was completely objective or neutral (an impossible goal!) in my teaching. Although some might argue that teachers should try nevertheless to be as politically objective and neutral as possible, avoiding discussions of sexism, this position is also an impossibility: avoidance is political because teaching is political (Stanley, 2001, p. 8). Avoiding teaching a certain linguistic form in order to be "neutral" is a choice that has an equally political weight as teaching the form. It is a political choice not to explain to EFL students the socio-cultural issues that affect how so-called "native speakers" make communicative choices, treating language as if all speakers ("natives" and "non- 
natives") used it in the same way for the same purposes (Peirce, 1990, p. 106; Beebe, 1998 , n.p.). Avoiding discussions about sexism is also a political decision; such globally diffuse and important debates should be confronted constructively and critically in lessons, not ignored (Stanley, 2001, p. 9). Those who support gender-equality teaching approaches suggest including texts on gender issues, citing women as experts on various topics, and exploring culturally different gender roles, conventions and expectations in EFL lessons. They assert that the teacher should be a role model who supports gender equality, for example by not tolerating sexist jokes or comments in the classroom (Shiokawa, 1998, p. 61-66). I have incorporated these ideas into my gender-equality approach to EFL teaching.

\section{5) Observations and analysis}

The content of the course introduced a variety of materials, topics and activities, all meticulously prepared with the double aim of avoiding or confronting sexist practices on the one hand, and encouraging the students to be empowered, critical thinkers on the other. It is beyond the scope of this article to analyze all of these activities and discussions; I shall therefore focus on lessons involving professions vocabulary and discussions of job-related gender stereotypes. First, we shall examine an activity involving gender-marked professions and the reactions of the students, followed by an analysis of an activity involving gender-unmarked professions and the students' reactions, and conclude with observations about the long-term manifestations and effects of the lexical items and related socio-cultural linguistic competences acquired.

\section{1) The first professions vocabulary worksheet: gender-marked language}

$$
\begin{array}{r}
\text { "Being called a 'poetess' brings out the 'terroristress' in me." - Adrienne Rich, } \\
\text { feminist poet }
\end{array}
$$

As we saw in Section 3, the teaching of profession-related vocabulary frequently reinforces gender stereotypes. Women, when portrayed at all, tend to be shown in supposedly "feminine" jobs (secretary, nurse, flight attendant, ballerina, teacher, etc.) and men in supposedly "masculine" jobs (doctor, lawyer, mechanic, engineer, police officer, etc.). These gendered examples may reflect an illustrator or writer's unconscious bias, associating a gender to a certain job, or they may be chosen on purpose, to "facilitate" the learning of new vocabulary through "easily recognizable stereotypes" that supposedly allow immediate and rapid identification of the information in the foreign language (Fiske, 1998, p. 357-411).

I prepared this activity with the conviction that it would be equally possible to teach professions vocabulary without using stereotyped representations of so-called masculine or feminine trades. The first worksheet I created was composed of a series of 
23 photographs of workers, approximately 50\% women and 50\% men. The following professions: doctor, police officer (policeman/woman), mechanic, architect, pilot, firefighter (fireman/woman), cook, mail carrier (postman/woman), engineer, judge and farmer, were represented by women, although gender stereotypes often associated with these professions usually link them to men. On the other hand, the following jobs: nurse, homemaker (housewife), musician, flight attendant (steward/ess), barber/hairdresser, dancer, librarian, lawyer, server (waiter/waitress), secretary, teacher and shop assistant, were represented by men, although many of these are stereotypically associated with women. Above the photographs was a list of the professions vocabulary in English. Since the majority of professions in English have one, gender-neutral form, 20 of the 23 words showed only one option. The three exceptions were steward/stewardess, waitress/waiter, and barber/hairdresser. As we saw in Section 3, for the professions ending in the suffix "-man" (e.g. policeman, fireman and postman), it is possible to create a female form by substituting "-man" with the morpheme "-woman" (e.g. policewoman, firewoman and postwoman). These forms can be found in English language dictionaries and are used by many "native speakers". However, they are not always taught in EFL courses since, in the strict grammatical sense, words ending in the morpheme "-man" are also inclusive of the female gender; as such it is "correct" to use a term ending in the suffix "-man" to refer to a woman (Miller and Swift, [1980] 2001, p. 30). There are also gender-neutral alternatives (e.g. police officer, firefighter and mail carrier). On the worksheet, however, I listed only the generic male term, intending to use it as a starting point to talk about other options. One final exception was the gendered word "housewife", for which there exists the gender-unmarked alternative "homemaker". The latter isn't often taught, probably due in part to socio-cultural stereotypes that view the profession as being a "woman's job". On the worksheet, I listed the commonly used word, "housewife", once again intending to use it as a starting point for discussion of other options.

\subsection{2) Reactions to the first activity, part I: job-related gender stereotypes}

The activity was carried out during the first lesson, on the $6^{\text {th }}$ of November, 2007. When I gave the worksheet to the students, I explained the various professions with gestures and descriptive phrases in English (for example, saying "A postman is a person who delivers letters" and pretending to deliver an envelope to a student), and asked them to find the photograph that matched the word being described.

For the professions stereotypically associated with men, such as mechanic, judge and engineer, or with women, such as teacher, the students never objected to the fact that a women could perform a so-called "man's job" or vice versa. In some photographs in which the biological sex or gender projected by the person was "unclear", for example (1) the secretary, a man with short hair but with few other physical indicators of biological sex or performed gender, (2) the farmer, a small image 
in which the woman's face was partially obscured by a hat and the clothing was not clearly identifiable as a dress, and (3) the engineer, a woman with a hardhat and hair held back in a ponytail at the nape of the neck, many students used the pronoun "he" in reference to the farmer and the engineer, and "she" in reference to the secretary. The choice of these pronouns may indicate the tendency to associate such types of work with a certain gender. Regarding the images in which the person was "more clearly" performing visually as a woman or man, the students never switched pronouns, even when the job was stereotypically associated with a different gender. It is also important to note that before I incited discussion on the matter, the students never questioned why a woman or man was performing a job stereotypically associated with a different gender. Finally, since the students had no problems in matching the photographs to the professions, it can be affirmed that the students were perfectly capable of understanding the new lexical items without depending on the gender stereotypes associated with they are associated.

With regards to the image of the doctor (a woman wearing white scrubs and a stethoscope, standing before a series of x-rays) and the nurse (a man wearing scrubs and a blue apron while measuring a patient's blood pressure), I must admit that it was not entirely clear who was performing a doctor's or nurse's duties (although my reasoning was that the doctor would examine the x-rays, not the nurse). With the exception of Nadya, the 36-year old Russian student, who insisted on associating the woman with the nurse's job, the other students discussed the ambiguity of the actions being performed in the images rather than insisting on the gender of the person as an indicator of the job. For example, one student suggested while referring to the image of the nurse, "he is with the patient, so he is the doctor", and another, referring to the image of the doctor with the stethoscope, "she has the, uh, stetoscopio, so she is the doctor". A similar situation occurred with the photograph of the architect (a woman seated behind a desk on which there were architectural floorplans and instruments such as a triangular ruler) and the engineer (a woman wearing a helmet standing near a construction site while holding up and reading some technical blueprints). Matteo, a 31-year old student, suggested that the image of the architect represented a secretary because she was seated behind a desk. The others, however, discussed the contextual clues that could distinguish the architect from the engineer, such as the presence of the instruments on the desk or the construction site visible in the background. In both cases, with the doctor/nurse and the architect/engineer/secretary, the students concentrated on the ambiguity with regards to the action being performed in the image, not the gender of the person. I believe the result of this activity shows that, at least as far as professions are concerned, the type of activity or action represented is much more important than workrelated gender stereotypes for understanding and acquiring new vocabulary.

\subsection{3) Reactions to the first activity, part II: professions with gender-marked forms}


When we came to the word "policeman", one student, Matteo, immediately remarked on the application of the suffix "-man" to the photograph of a woman. I explained that in the strict grammatical sense, the term "policeman" also includes women, but that it would also be correct to use "policewoman". The students expressed concern over which was more grammatically correct, and I reassured them that both were valid options grammar-wise. They then asked which word was more used by "native speakers". I responded to this question by affirming that people who speak English as a first language use both lexical items, but that many people, especially women (particularly since the feminist movement in the 1970s, although the suffix "woman" has existed for many professions for over 300 years), prefer to use "policewoman" because they consider the use of "policeman" to be sexist when referring to a woman (Miller and Swift, [1980] 2001, p. 30-31). I proceeded to reassure the students that both forms were grammatically correct, and that they could choose the form they preferred and deemed most appropriate in a given situation.

The students' worries about the lack of the gendered form "policewoman" on the worksheet shows how people today, particularly young people, are more sensitive to issues of gender and sexism expressed through language. One could argue that for "native" speakers of Italian, a language that relies more heavily on gendered inflections and forms than English, it is more "natural" to search for a female term to correspond to a male one; however, this argument is weak in relation to professions vocabulary, since many lexical terms for jobs in Italian have only one, male-gendered form. It is more likely that the students' linguistic choices reflect an awareness of and sensitivity to both the issue of sexism and the current linguistic debate in Italy regarding the creation of female-gendered lexical items to replace or complement the male-gendered ones ${ }^{\mathrm{iii}}$.

Continuing with the professions vocabulary activity, we came to observe the photograph of the firefighter and the mail carrier. The students, based on our previous discussions, immediately suggested "firewoman" and "postwoman" instead of "fireman" and "postman" as was written on the worksheet. They reflected on the lexical terms and used them to re(ad)dress the feminine (Irigaray, [1975] 1993, p. 138). With regards to the image of the firefighter, pictured as a woman in a side-profile with her hair tied back, Simone, a 37-year old student, suggested with conviction that it could also be a thin man with long hair, challenging hegemonic, stereotyped notions of masculine corporality. This observation provoked a few giggles, but the majority of the students reflected on the idea with the same seriousness with which Simone had proposed it. His observation and their accepting reactions are evidence of the knowledge and recognition of non-hegemonic male physiques that break corporal gender stereotypes.

The photograph that caused the most "hubbub" was that of the homemaker. After listening to the definition "a housewife is a person who takes care of the home and family", the students immediately indicated the photograph of the homemaker, a man cleaning a kitchen floor with a mop. Matteo immediately questioned the term 
"housewife", saying "but 'wife' means 'moglie', no?", checking the translation in Italian and recognizing that the word seemed inadequate for referring to a man. I explained that, similar to the case of "policeman", "housewife" is technically the name of the profession and thus inclusive of both women and men. I then asked the students if they could think of other possibilities, and one suggested replacing the morpheme "wife" with its male-gendered equivalent "-husband" to make "househusband". I praised the student for the good idea, then explained that although the word exists in colloquial English, it frequently has a derogatory connotation for the man in question. As with "policeman" and "policewoman", the students insisted on finding a word that was both grammatically correct and adequate for the subject; this time with more ardor, since the solution was not found as easily as with substituting the suffix "-man" with "-woman". This behavior demonstrates a strong sensitivity to questions of sexist uses of language. We continued the discussion during the next lesson's activity, which we shall now consider.

\section{2) The second professions worksheet: gender-unmarked language}

After concluding the first professions activity, discussing also other terms ending in the suffix "-man" such as businessman, chairman, congressman, sportsman and salesman, in the next lesson, held on the $8^{\text {th }}$ of November, 2007, we began a more in-depth activity including a new worksheet on professions and gender-neutral terms. The new worksheet was structured as a list of gender-unmarked alternatives to the gender-marked professions we saw in the previous lesson, for example "police officer" instead of "policeman", "firefighter" for "fireman" and "mail carrier" for "mailman", as well as "server" instead of "waiter/waitress", "flight attendant" for "steward/ess" and "homemaker" for "housewife". The students were asked to find the gender-marked version of the gender-unmarked words.

Using the discussion from the previous lesson as a starting point, we talked about what was the "best" option (in regards to grammatical correctness, avoiding sexist usages of language, etc.) to use when referring to, for example, a female police officer. We directly confronted the issue of sexist uses of language, using a simplified version of Parks and Roberton's definitions of sexist language: that sexist language is words, phrases and expressions that unnecessarily differentiate between women and men, and excludes, trivializes or diminishes either gender (1998, p. 445), although in Englishspeaking societies it tends to have more negative effects on women $(2000$, p. 1).

\subsection{1) Reactions to the second activity, part I: sexism and modifiers}

As we observed previously, sexist uses frequently stem from names of professions. Adding to our discussions on the use of the suffixes "-man" and "-woman", we also considered the role of the free morphemes "man", "woman", "female" and 
"male" as modifiers, for example "the woman doctor" or "the male nurse". Such combinations, present both in the Italian (see Sabatini, 1987, p. 113-123) and English (see Miller and Swift, [1980] 2001, p. 66-71) languages, can be seen as having sexist connotations because they highlight the idea that the person is performing a job that is "unusual" or "inadequate" in relation to their gender identity. The students and I discussed that these forms are grammatically correct, but may be offensive to certain individuals who prefer to be referred to simply as "doctors" rather than "women doctors" or "nurses" rather than "male nurses".

\subsection{2) Reactions to the second activity, part II: excluding women from a group}

Referring to a singular individual, one student asked if it were preferable to use "policeman/woman" or "police officer". I repeated that all the options were grammatically correct, but when another student expressed concern about potentially offending someone, I explained that generally neither the gender-marked term nor the gender-unmarked term were offensive. For example, "Sara is a policewoman" or "Daniel is a policeman" generally have the same effect as "Sara is a police officer" and "Daniel is a police officer" when referring to one individual. However, when we refer to a group of men and women, some speakers do consider it offensive to use only the masculine generic form to refer to a group of women and men (Swift and Miller, [1980] 2001, p. 34). I called the students' attention to the fact that in some situations Italian speakers use a masculine generic whereas English speakers do not, as is the case with "I was at my uncles"'. Here, an English speaker would understand that the interlocutor had visited the home of her or his (male) uncles, not the home of an aunt and uncle. The latter, however, is how the similar phrase in Italian, "Sono stata dai miei zii", would be interpreted despite the use of the masculine plural form ("zii"). Similarly, in English one often sees sentences in which women are "forgotten", and one cannot be sure if the "inclusive" masculine generic is being employed or if reference is being made only to men. For example, "Almost 300,000 postmen work for the Royal Mail Services" could be interpreted as (1) there are 300,000 male postal workers, or (2) there are 300,000 male and female postal workers. In order to avoid such ambiguities and potential discrimination, one could use "postwomen and postmen" or "mail carriers" or "postal workers".

The second part of the worksheet consisted of a series of sentences that excluded or discriminated against women or men. Sentences of three types were used: ones in which a gender-marked word was used to indicate someone of a noncorresponding gender (for example, "Debbie is a good salesman" or "George is a housewife", ones in which a modifier was used unnecessarily (for example, "Brendan is a male secretary"), and ones in which a gender-marked (male) word was used to refer to a mixed group (for example, "Anthony, Jason, Christine and Lauren are stewards". I asked the students to modify the sentences that they thought were unclear or could be 
potentially offensive to a person or group, also offering the possibility of not making any modifications. Most students changed all of the sentences, preferring the genderunmarked form to a gender-marked one (for example, "Debbie is a good salesperson" rather than leaving "salesman" or substituting it with "saleswoman", and "Anthony, Jason, Christine and Lauren are flight attendants", rather than leaving "stewards" or replacing it with "stewards and stewardesses").

\section{3) Empowered choices: the long-term impact}

Although the first two lessons were the only ones that focused specifically on professions vocabulary and job-related gender stereotypes, the students continued to use the knowledge they acquired at other times throughout the rest of the course, making critically thought-out decisions about what terms to use. We shall briefly examine two instances in which the topic resurfaced.

\subsection{1) Revisiting the "police officer" issue}

During the eleventh lesson, on the $23^{\text {rd }}$ of November, 2007, the students engaged in an activity whose main objective was to converse with a partner regarding their current professional ambitions and compare those to the job-related desires they had had as children. Arianna, 23 years old, and Federico, 32 years old, worked together:

\footnotetext{
Arianna: I have always wanted to be... [pauses while apparently searching for the word; cannot remember in English so she uses Italian:] poliziotta.

Federico: Policeman.

Arianna: $\quad$ No... [frowns and looks at me, presumably asking for help]

Teacher: Or policewoman?

Arianna: $\quad$ Uh... No, police officer.
}

When given the possibility of using any of three options to express an idea, Arianna chose to use the gender-unmarked term, remembering the vocabulary learned during the first two lessons and making an informed, empowered choice, opting for the term she considered most adapt for the situation and the idea she wanted to convey.

\subsection{2) Results of the final exam:}

For the final exam of the course, I included an exercise in which it was necessary to read a definition in English and write the corresponding profession in the space next to it. First, for the definition "a person who serves food in a restaurant", three students used the gender-unmarked lexical item "server", three the gender-marked male

$$
\begin{gathered}
\text { Rua Marquês de São Vicente, } 225 \text { Gávea/RJ CEP 22453-900 Brasil } \\
\text { Ano 2011. Número 13. ISSN 1679-6888. } \\
\text { escrita@puc-rio.br }
\end{gathered}
$$


form ("waiter"), one the gender-marked female form ("waitress"), two both the gendermarked female and gender-unmarked forms ("waitress/server"), and one both gendermarked forms ("waiter/waitress"). Second, for the definition "a person who delivers letters and postcards", seven students chose the gender-marked male form ("postman") and three the gender-unmarked form ("mail carrier"). Finally, for the definition "a person who protects the public and fights criminals", five students opted for the genderunmarked word ("police officer"), three the gender-marked male form ("policeman"), and two suggested justifiable alternatives ("detective" and "lawyer"). The answers show a general tendency towards the gender-unmarked lexical items, followed by the gendermarked male forms. The absence of wrong answers (words unrelated to the definitions) or spaces left blank suggests that the students were not confused or "negatively impacted" by the "extra" vocabulary taught during the lessons; they assimilated the various options and chose to use the ones they considered most appropriate in different contexts.

\section{6) Conclusions}

The students involved in the action research project confirmed my initial hypothesis that they would be just as capable of assimilating diverse modes of expression relative to each new topic without relying on representations of gender stereotypes, despite the traditional ideas that EFL learners should not be taught "too many" options so as to avoid confusion and that stereotypes facilitate EFL learning (Fiske, 1998, p. 357-411). In this article, we focused on how the students successfully acquired the multiple gender-marked and gender-unmarked options to speak about professions.

Although the students initially showed concern about using the "most grammatically correct" forms, after being reassured about the correctness of the various options and discussing the importance of choosing contextually appropriate forms, they quickly moved their focus of concern to the socio-cultural and political context of the words and how to use them in adequate and non-sexist ways in different situations. Throughout the course, the students thought critically about the various options and made empowered choices as to how to express themselves in different situations.

I also observed that the students were already sensitive to issues of sexist uses of language, particularly as they never questioned why certain people were shown performing jobs stereotypically associated with different genders or representations of people with non-stereotypical or non-hegemonic gender performances, and because they insisted on finding gender-unmarked terms when they were not provided. This highlights the necessity of adapting teaching approaches to students' current sensitivities, interests and concerns over politically correct or contextualized uses of language; in other words, of adopting a flexible, student-centered postmethod pedagogy fit for a certain group of learners. As Silva summarizes, "choosing a postmethod 
pedagogy allows the professor-researcher to theorize and practice in accordance with local reality" (2004: n.p., my translation).

It is beyond the scope of this article to analyze all of the activities realized and the topics discussed in class. Although here I have chosen to examine the students' reactions to certain lexicon-related activities, in the future it will be equally interesting to analyze the data collected on their performances on other topics and in role plays and dialogues. With regards to future extensions of this project, I believe it will be important to further deconstruct the concept of gender, including more discussions of subversive gender performances and gender identity (such as discussions on genderqueer, transgendered people, transsexuals, etc.).

In conclusion, as we have seen, the students involved in this project frequently expressed preferences and made informed, carefully weighed linguistic choices that promoted gender equality. They were ready, capable and motivated to make the foreign language their own, expressing themselves as they deemed appropriate, and to think critically about gender stereotypes and respectfully discuss the "hot" political topics of sexism and gender equality. Sensitivity to sexism and the ability to learn multiple options for self expression demonstrated by this group of students, show the importance of language courses in which teachers use materials that promote gender equality (or confront and deconstruct gender stereotypes in materials that do not) and apply approaches that encourage students to be informed, critical thinkers so that they may make empowered linguistic choices.

\footnotetext{
${ }^{\mathrm{i}}$ Similar suggestions have been made in Italian handbooks on nonsexist writing (see Sabatini, Il sessismo nella lingua italiana, 1987, p. 107).

ii It is important to mention that many publishing houses have improved the quality of their materials in recent years, showing more equal opportunities with regards to gender, multiculturalism, disability or special needs, etc. Some have also instituted quota systems to ensure equal quantitative representation (Stanley, 2001, p. 2-7). However, materials that perpetuate sexist stereotypes are still produced, and teachers should carefully evaluate the materials used in each course to avoid their reinforcement.

iii For example, the debate in Italy with regards to lawyer expressed as "avvocato", "avvocatessa" or "avvocata". "Avvocato" is a male-inflected form traditionally used for both men and women. One alternative present in Italian dictionaries, "avvocatessa", has come under fire from feminists since, despite being female-inflected, it also has the diminutive suffix "-essa", literally meaning "a little female lawyer". Feminists and gender-equality linguistics scholars have claimed that this form is demeaning and have thus proposed the alternative "avvocata", a term that, although it is gaining in popularity among female lawyers, is not yet recognized as correct by grammar institutions (see Sabatini, 1987).
}

\section{Bibliographical References}

BEEBE, Jacqueline D. "Sexist Language and English as a Foreign Language: A Problem of Knowledge and Choice." In The Language Teacher, 1998. http://www.jaltpublications.org/ttt/files/98/may/beebe.html, accessed on 18/10/2007, at 21:12:20. 
BENSON, P. "The philosophy and politics of learner autonomy". In BENSON, P. and VOLLER, P. (eds). Autonomy and independence in language learning. London: Longman, 1997. pp. 18-34.

BROWN, H. D. "Requiem for methods". Journal of Intensive English Studies, 7, 1993, p. 1-12.

. "English language teaching in the 'post-method' era: Toward better diagnosis, treatment, and assessment”. PASAA (Bangkok) 27, 1997, p. 1-10.

CAMERON, D. "Verbal hygiene for women: Linguistics misapplied?" Applied Linguistics, 15 (4), 1994, p.382-398.

FISKE, Susan T. "Stereotyping, prejudice, and discrimination". In GILBERT, D. T. FISKE, S. T. and LINDZEY, G. (eds), Handbook of social psychology. 4th ed., Vol. 2. New York: McGraw-Hill, 1998. pp. 357-411.

HARTMAN, P. L. and JUDD, E. L. "Sexism and TESOL Materials". In TESOL Quarterly, 12, p. 383-393.

HELLINGER, M. "For men must work, and women must weep: Sexism in English language textbooks used in German schools". In KRAMERAE, C. (ed), The voices and words of women and men. New York: Pergamon Press, 1980. pp. 267-274.

IRIGARAY, Luce. Speculum: L'altra donna. Milano: Universale Economica Feltrinelli, [1975, 1989] 1993. (Original title: Speculum de l'autre femme. Paris: Les Editions de Minuit, 1974.)

KUMARAVADIVELU, B. "The post-method: (E)merging strategies for second/foreign language teaching". In: TESOL Quarterly, No. 28, Vol. 1, Spring 1994, p. 27-48.

p. 161-176.

. "Toward a postmethod pedagogy". In: TESOL Quarterly, No. 35, 2001,

KUO, Junmin. "Teaching ESL/EFL Students to Recognize Gender Bias in Children's Literature". In The Internet TESOL Journal, vol XI, no.11, novembre 2005. http://iteslj.org/Articles/Kuo-GenderBias.html, accessed on 18/10/2007 at 20:56:36.

MAgGiO, Rosalie. The Nonsexist Word Finder: A Dictionary of Gender-Free Usage. Phoenix: The Oryx Press, 1987.

MILLER, Casey and SWIFT, Kate. The Handbook of Nonsexist Writing. San Jose: iUniverse.com, Inc., [1980] 2001.

PAPA, Mario and SHELLY, Janet. Spotlight on You. Book 1: Your Way to European Certifications. Bologna: Zanichelli editore S.p.A, 2004. 
PARKS, Janet B. e ROBERTON, Mary Ann. "Contemporary Arguments Against Nonsexist Language: Blaubergs (1980) Revisited". In Sex Roles: A Journal of Research, 39, 1998, p. 445-461.

. "Development and Validation of an Instrument to Measure Attitudes Toward Sexist/nonsexist Language". In Sex Roles: A Journal of Research, March 2000 .

PEIRCE, B. N. "Comments on Bronwyn Norton Peirce's "Toward a pedagogy of possibility in the teaching of English internationally: People's English in South Africa": The author responds..." TESOL Quarterly, 24, 1990, p.105-112.

29, 1995, p.9-31.

"Social identity, investment, and language learning". TESOL Quarterly,

PORRECA, K. L. "Sexism in current ESL textbooks". TESOL Quarterly, 18(4), 1984, p. $704-724$.

RICHARDS, J. C. and RODGERS, T. Approaches and Methods in Language Teaching. New York: Cambridge University Press, 2001.

SABATINI, Alma. Il sessismo nella lingua italiana. Roma: Commissione Nazionale per la Realizzazione della Parità tra Uomo e Donna, Istituto Poligrafico e Zecca dello Stato, 1987.

SAKITA, T. "Sexism in Japanese Education: A Survey of EFL Texts." Women and Language. 18 (2), 1995, p 5-12.

SHIOKAWA, Haruhiko. "Gender Issues and TESOL: Literature Overview”. SURCLE, Vol I, 1998, p.61-66.

SILVA, Gisvaldo Araújo. "A era pós-método: o professor como um intelectual”. [n.p.]: Revista Linguagens e Cidadania, edição n. 12, 12/2004. Available at: http://www.ufsm.br/lec/02 04/Gisvaldo.htm. Accessed on 17/08/2011 at 19:00:00.

SPENDER, Dale. Man-made Language. London: Routledge, 1980.

STANLEY, Karen (ed). "Sexist Language in ESL/EFL Textbooks and Materials." In TESL-EJ Teaching English as a Second or Foreign Language. Vol. 5, No. 1. April 2001. p.1-11.

SUNDERLAND, Jane. "Gender in the EFL Classroom”. ELT Journal, 46 (1), 1992, p.81-91.

WOLFSON, N. Perspectives: Sociolinguistics and TESOL. Cambridge: Newbury House, 1989. 